\title{
Cultivo de plantas de Erythrina velutina em substrato contendo vermicomposto
}

\author{
Larissa Morais SENA ${ }^{1}$, Julyanne Fonteles de ARRUDA ${ }^{1}$, Paulo Ovídio Batista de BRITO ${ }^{1}$, \\ Francisca Raíssa da Silva COSTA ${ }^{1}$, Roberto Albuquerque PONTES FILHO ${ }^{1}$, \\ Franklin Aragão GONDIM ${ }^{1 *}$
}

\author{
${ }^{1}$ Instituto Federal de Educação, Ciência e Tecnologia do Ceará, Maracanaú, CE, Brasil \\ *E-mail: aragaofg@yahoo.com.br \\ (Orcid: 0000-0003-0097-2080; 0000-0003-4105-9597; 0000-0001-8978-8241; \\ 0000-0002-0805-4906; 0000-0001-8670-3185; 0000-0002-7168-2358)
}

\begin{abstract}
Recebido em 09/04/2020; Aceito em 24/06/2021; Publicado em 15/07/2021.
RESUMO: Uma técnica muito utilizada para recuperação de áreas degradadas é o plantio de mudas, uma espécie que apresenta um grande potencial é o Mulungu. Além disso, na recuperação de áreas degradadas se faz necessário o uso de fertilizantes para o solo, assim a produção de fertilizantes por meio de compostagem, mostra-se uma técnica sustentável e de baixo custo. O objetivo deste trabalho foi analisar a eficiência da fertilização pelo material proveniente de compostagem seguido por vermicompostagem no cultivo de plantas de Mulungu. Realizou-se um experimento, na casa de vegetação do IFCE campus Maracanaú, utilizando diferentes substratos: $100 \%$ areia (em volume), 50\% húmus comercial, 100\% húmus comercial, 50\% composto orgânico, $75 \%$ composto orgânico e 100\% composto orgânico. As plantas foram coletadas e foram analisadas: as produções de matéria fresca e seca e a quantificação dos teores de solutos orgânicos. Verificou-se que o crescimento das plantas e a produção de solutos orgânicos estão ligados diretamente ao teor de nitrogênio no solo, de forma que a escassez de nitrogênio é um fator limitante para o adequado crescimento do Mulungu. Nas condições experimentais empregadas, verificou-se que o tratamento contendo $75 \%$ composto orgânico ocasionou o maior crescimento das plantas de Mulungu.
\end{abstract}

Palavras-chave: nutrientes; nitrogênio; solutos orgânicos; matéria fresca; matéria seca.

\section{Cultivation of Erythrina velutina plants in substrate containing vermicomposts}

\begin{abstract}
A technique widely used to recover degraded areas is the planting of seedlings, a species that has great potential is Mulungu. In addition, in the recovery of degraded areas it is necessary to use fertilizers for the soil, so the production of fertilizers by means of composting is shown to be a sustainable and low-cost technique. The objective of this work was to analyze the efficiency of fertilization by material from composting followed by vermicomposting in the cultivation of Mulungu plants. An experiment was carried out in the greenhouse of the IFCE campus Maracanaú, using different substrates: 100\% sand (by volume), 50\% commercial humus, $100 \%$ commercial humus, $50 \%$ organic compost, $75 \%$ organic compost and $100 \%$ compost organic. The plants were collected and analyzed: the production of fresh and dry matter and the quantification of the levels of organic solutes. It was found that the growth of plants and the production of organic solutes are directly linked to the nitrogen content in the soil, so that the lack of nitrogen is a limiting factor for the adequate growth of Mulungu. In the experimental conditions employed, it was found that the treatment containing $75 \%$ organic compost caused the greatest growth of Mulungu plants.
\end{abstract}

Keywords: nutrients; nitrogen; organic solutes; fresh matter; dry matter.

\section{INTRODUÇÃO}

A recuperação de áreas degradadas consiste na aplicação de técnicas agronômicas ou de engenharia com o objetivo de restabelecer a vegetação de uma área impactada que sofreu algum forte distúrbio ambiental através de ações antrópicas ou naturais (ARAÚJO et al., 2005).

O substrato é imprescindível na recuperação de áreas degradadas, para a produção de mudas, e suas propriedades físicas, químicas e biológicas determinarão a qualidade final das mudas a serem transplantadas. Uma forma de suprir a demanda por substratos é a utilização de resíduos e subprodutos de composição orgânica que estejam disponíveis (PEREIRA et al., 2020).

Um dos fertilizantes mais adequados e utilizados nesses casos é o composto proveniente de compostagem. Além do tratamento de resíduos orgânicos, a compostagem produz um material que pode ser colocado novamente no ciclo de produção, um fertilizante rico em nutrientes, que auxilia na retenção de umidade, melhora a textura do solo e fornece macro e micronutrientes à planta (LOUREIRO et al., 2007). É essencial a ampliação dos estudos a respeito desse fertilizante para o manejo de solos degradados, uma vez que é um método ecologicamente correto e de baixo custo (CARLESSO et al., 2011).

A compostagem é um processo controlado, caracterizado pela decomposição aeróbia da matéria orgânica através dos microorganismos, no qual ocorre a mineralização da matéria orgânica para estabilização e fácil assimilação pelas plantas (PEDROSA et al., 2013). Para uma maior eficiência, realiza- 
se em seguida a vermicompostagem. Esta técnica é feita através da ação combinada de minhocas e microrganismos presentes no seu trato digestório, aumentando-se assim a eficiência do tratamento e a qualidade nutricional do material. Portanto, após o tratamento, esse material pode ser adicionado como fertilizante ao solo (ORRICO JÚNIOR et al., 2012).

Um dos principais fatores de degradação é o desmatamento, pois a retirada da cobertura vegetal interfere nos diferentes ciclos biogeoquímicos e no equilíbrio dinâmico dos ecossistemas (LIMA et al., 2018). Devido ao grau avançado de degradação dos biomas do semiárido nordestino, especialmente a caatinga, uma alternativa para a recuperação é utilizar espécies de plantas nativas, que já são adaptadas às características da região, como por exemplo a Erythrina velutina (SILVA et al., 2016).

A Erythrina velutina, popularmente conhecida como mulungu, é uma Fabaceae de porte arbóreo, que atinge alturas de 8 a $12 \mathrm{~m}$, além de ser decídua e heliófila. A espécie ocorre desde o estado do Ceará até o de São Paulo, e é comum em várzeas úmidas e margens de rios da Caatinga (CUNHA; GOMES, 2015). A árvore é usada principalmente na medicina popular (RIBEIRO et al., 2006), e existem estudos que demonstram a presença de propriedades calmantes que ajudam na insônia e em outros distúrbios do sistema nervoso central (AGRA et al., 2007), além de ser utilizada no tratamento de inflamação e coagulação intravascular disseminada (MONTEIRO, 2011).

A espécie apresenta um grande potencial para recuperação de áreas degradadas, pois possui características como tolerância à seca, rápido crescimento e capacidade de fixação de nitrogênio (CARVALHO, 2008).

No Brasil, um dos desafios da recuperação de áreas degradadas é a dificuldade de se produzir mudas de boa qualidade. A produtividade das plantas depende dos elementos de nutrição mineral disponíveis no solo. Portanto, para a produção de mudas se faz necessário o uso de substratos de qualidade (OLIVEIRA et al., 2017).

O objetivo deste trabalho foi analisar a eficiência da fertilização pelo material proveniente de compostagem seguida por vermicompostagem no cultivo de plantas de Mulungu. Foram analisadas: as produções de matéria fresca e seca e a quantificação dos teores de solutos orgânicos (carboidratos, $\mathrm{N}$-aminossolúveis, prolina livre e proteína solúveis).

\section{MATERIAL E MÉTODOS}

Nesse quesito, devem ser descritos sistematicamente os materiais, equipamentos e as metodologias utilizadas para o desenvolvimento do trabalho. Esses aspectos devem ser apresentados de modo que outros pesquisadores ao consultarem o artigo consigam reproduzi-lo com base apenas no que fora descrito no trabalho.

Deve ser organizado, de preferência, em ordem cronológica, evitando detalhes supérfluos e extensas descrições de técnicas de uso corrente (nesses casos apresentar citações).

O experimento foi conduzido a partir de junho de 2018 na Casa de Vegetação do Instituto Federal de Educação Ciência e Tecnologia do Ceará (IFCE) Campus Maracanaú, ambiente isolado do meio externo e totalmente coberto por tela de nylon de cor preta que proporcionou sombreamento de $50 \%$ em relação à área exterior. As médias de temperatura e umidade relativa do ar, durante o dia, dentro do telado, foram, respectivamente, $31,3{ }^{\circ} \mathrm{C}$ e $59 \%$.

O composto utilizado para fertilização foi produzido anteriormente, através de um experimento do Laboratório de Bioquímica e Fisiologia Vegetal do IFCE Campus Maracanaú. O experimento foi realizado em duas etapas (compostagem seguida de vermicompostagem), no IFCE. Foram utilizados resíduos orgânicos alimentares, provenientes da Central de Abastecimento do Ceará (CEASA - CE), esterco bovino e folhas secas. Aos 51 dias após o início da compostagem, o composto foi colocado em um depósito com capacidade de $310 \mathrm{~L}$ e foram adicionadas 100 minhocas californianas (Eisenia foetida) adultas, iniciando assim o processo de vermicompostagem. Ao todo o processo durou 150 dias (SENA et al., 2019). Os teores de Nitrogênio total no composto orgânico obtido e no húmus de minhoca comercial utilizados na formulação dos substratos para as plantas foram de 10,5 e 8,9 g.kg-1, respectivamente.

No experimento com plantas o delineamento experimental foi o inteiramente casualizado, constituído por seis tratamentos em vasos de $5 \mathrm{~L}$ preenchidos com: 100\% areia (em volume); $50 \%$ húmus comercial $+50 \%$ areia; $100 \%$ húmus comercial; $50 \%$ composto $+50 \%$ areia; $75 \%$ composto $+25 \%$ areia e $100 \%$ composto, com cinco repetições cada.

Os substratos foram homogeneizados, acondicionados em vasos de plástico de $5 \mathrm{~L}$ e adicionadas três sementes de Mulungu por vaso. As sementes passaram anteriormente por procedimento de quebra de dormência, através de escarificação mecânica usando lixa número 10. A irrigação foi realizada diariamente à $50 \%$ da capacidade de campo conforme Martins et al. (2016).

Aos 12 dias após a semeadura (DAS) realizou-se o desbaste de parte das plantas, deixando-se apenas uma por vaso, para evitar a competição por nutrientes. Aos 21 DAS foi feita a primeira coleta, e aos 33 DAS a $2^{\circ}$ coleta.

Após as coletas, as amostras foram encaminhadas para o Laboratório de Bioquímica e Fisiologia Vegetal, onde foram feitas as análises de matéria fresca e seca e determinação dos teores de solutos orgânicos solúveis (carboidratos, Naminossolúveis, prolina e proteínas solúveis).

No laboratório, todas as plantas coletadas foram limpas para retirada do substrato das raízes e cortadas para separação em parte aérea (folhas + caules) e raízes. Para a análise de matéria fresca e seca, foi feita a pesagem da matéria fresca em balança analítica, e, após 72 horas à $60^{\circ} \mathrm{C}$ na estufa com circulação forçada de ar, pesou-se a matéria seca.

Para realização das análises bioquímicas, foi produzido o extrato das folhas e das raízes. Utilizou-se a proporção $0,5 \mathrm{~g}$ de matéria seca para $5 \mathrm{ml}$ de água destilada. O material foi macerado por três minutos com auxílio de almofariz e pistilo e, em seguida, filtrado em tecido de malha fina. Após este processo, procedeu-se a centrifugação do material a $12000 \mathrm{xg}$ por 15 minutos para a obtenção de extrato límpido.

A análise de carboidratos solúveis foi feita adicionandose a tubos de ensaios $15 \mu \mathrm{l}$ de extrato, $485 \mu \mathrm{l}$ de água destilada, $500 \mu \mathrm{l}$ de solução de fenol a $5 \%$ e $2500 \mu \mathrm{l}$ de ácido sulfúrico concentrado. Em seguida, os tubos foram agitados e colocados em repouso até a obtenção da temperatura de $25^{\circ} \mathrm{C}$. Logo após, foi realizada a leitura em espectofotômetro à $490 \mathrm{~nm}$.

A análise de $\mathrm{N}$-aminossolúveis foi realizada adicionandose a tubos de ensaios $40 \mu \mathrm{l}$ de extrato, $60 \mu \mathrm{l}$ de água destilada, $300 \mu \mathrm{l}$ de tampão citrato $0,2 \mathrm{M}, 600 \mu \mathrm{l}$ de $\mathrm{KCN} 0,2 \mathrm{nM}$ e 120 
$\mu \mathrm{l}$ de ninhidrina 5\%. Em seguida, foram fechados os tubos e agitados em agitador de tubos de ensaio. Depois, os tubos foram colocados em banho-maria a $100{ }^{\circ} \mathrm{C}$. Após 20 minutos foram colocados em banho de gelo, e adicionados $780 \mu \mathrm{l}$ de etanol $60 \%$. Então, foi feita a leitura em espectofotômetro à $570 \mathrm{~nm}$.

Para as análises de proteínas solúveis adicionaram-se aos tubos de ensaio $20 \mu \mathrm{l}$ de extrato, $80 \mu \mathrm{l}$ de água destilada e $1000 \mu \mathrm{l}$ de solução Bradford. Logo em seguida, esses tubos foram agitados e, após 15 minutos, foi feita a leitura no espectofotômetro à $595 \mathrm{~nm}$.

$\mathrm{Na}$ análise de prolina foram adicionados aos tubos de ensaio $320 \mu \mathrm{l}$ de extrato, $80 \mu \mathrm{l}$ de água destilada, $400 \mu \mathrm{l}$ de ácido acético e $400 \mu \mathrm{l}$ de ninhidrina. Logo após, os tubos foram agitados e colocados no banho-maria a $100^{\circ} \mathrm{C}$. Após 1 hora, os tubos foram colocados no banho de gelo, e em seguida foi adicionado $800 \mu \mathrm{l}$ de tolueno, e novamente foi feita a agitação dos tubos. A parte menos densa foi aspirado e colocada na cubeta para leitura no espectofotômetro à 520 $\mathrm{nm}$.

De posse das leituras espectofotometricas das amostras, os cálculos dos teores de carboidratos, $\mathrm{N}$-aminossolúveis, proteínas e prolina foram obtidos, tendo como referência a equação obtida a partir da curva padrão.

Todos os dados foram submetidos à análise de variância (ANOVA), e as médias comparadas pelo teste de Tukey $(\mathrm{P} \leq$ $0,05)$ através do programa de análise estatística. Então, foram feitos os gráficos em software para elaboração de gráficos científicos.

\section{RESULTADOS}

Os resultados de matéria fresca e seca encontram-se nas Figuras 1 e 2. Para a matéria fresca das raízes (MFR), Figura 1A, observou-se que aos 21 dias após a semeadura (DAS) se destacaram os tratamentos contendo 50, 75 e 100\% de composto orgânico, e, os três tratamentos não diferiram significativamente entre si. Aos 33 DAS houve o destaque apenas dos tratamentos 75 e 100\% de composto orgânico, não havendo diferenças significativas entre eles. Para a matéria fresca da parte aérea (MFPA), Figura 1B, os maiores valores foram detectados nos tratamentos contendo 50 e $75 \%$ de composto aos 21 e 33 DAS. Para a matéria fresca total (MFT), Figura 1C, destacou-se aos 21 DAS o tratamento contendo, $75 \%$ de composto, que foi $300 \%$ maior que o tratamento areia, e, aos 33 DAS aqueles contendo 50 e $75 \%$ de composto, tiveram um aumento de mais de $200 \%$ se comparados ao tratamento a areia.

Para a MSR, Figura 2A, observou-se que aos 21 DAS se destacou o tratamento $75 \%$ de composto. Aos 33 DAS os maiores valores foram encontrados nos tratamentos com 75 e $100 \%$ de composto orgânico, e não diferiram significativamente entre si. Para a MSPA, Figura 2B, destacaram-se os tratamentos com 50, 75 e 100\% de composto aos 21 e 33 DAS. Já para a MST, Figura 2C, os maiores valores foram observados nos tratamentos $50,75 \mathrm{e}$ $100 \%$ de composto orgânico aos 21 DAS, sendo, em média, $200 \%$ maiores do que o tratamento areia. Aos 33 DAS, para os tratamentos, 75 e 100\% de composto orgânico houve um aumento de mais de $210 \%$ em relação ao tratamento areia.

Os resultados para os teores de solutos orgânicos encontram-se presentes nas Figuras 3 e 4, eles são referentes a $2^{\circ}$ coleta $(33 \mathrm{DAS})$. Em relação aos teores de proteínas solúveis nas folhas, o tratamento $75 \%$ de composto orgânico se destacou (Figura 3A), sendo 30\% maior do que o areia. Para os carboidratos solúveis, Figura $3 \mathrm{~B}$, os tratamentos $50 \%$ e $75 \%$ de composto orgânico se destacaram, aumentando, em média $43 \%$ em relação ao tratamento controle. A produção de prolina, Figura 3C, foi maior nos tratamentos contendo 50 e $75 \%$ de composto orgânico, com incremento da ordem de $60 \%$ em relação às plantas controle. Em relação à concentração de $\mathrm{N}$-aminossolúveis não houve variações significativas entre os tratamentos.

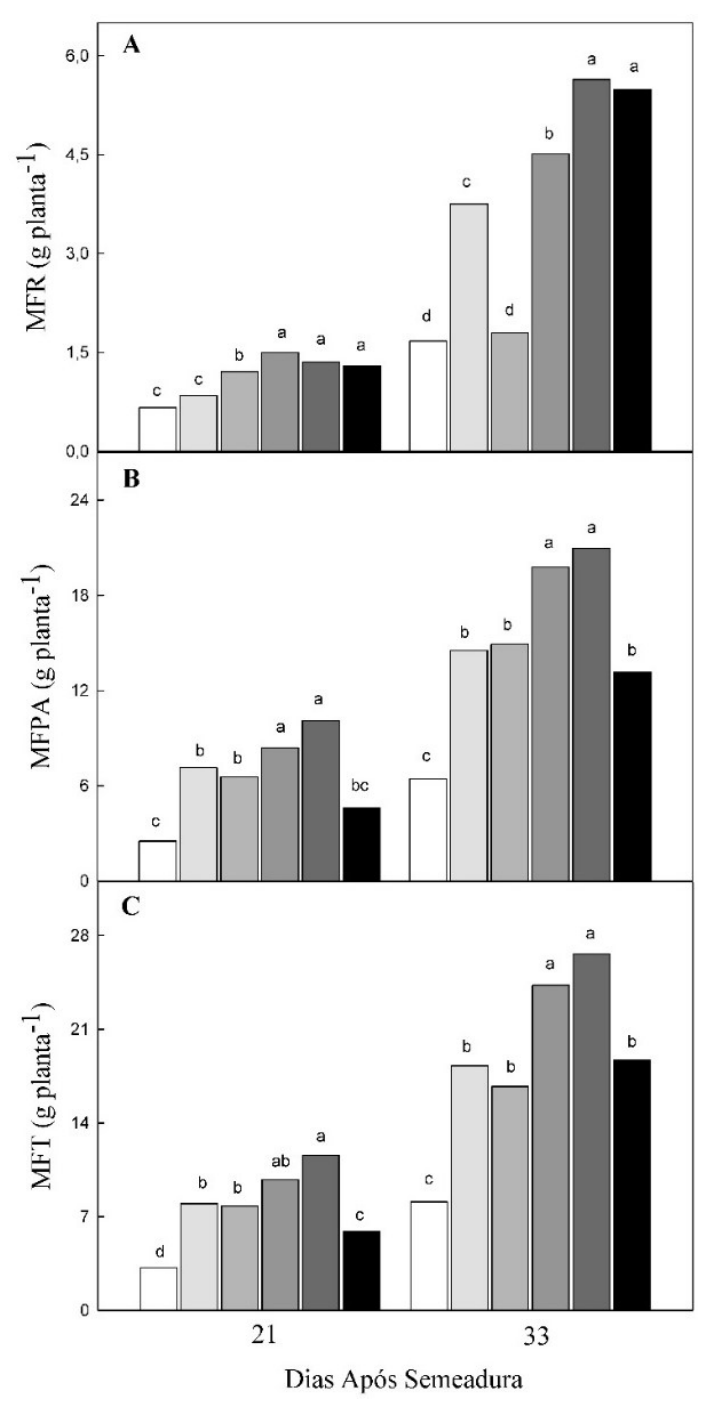

Figura 1. Matéria fresca das raízes (MFR) - A, da parte aérea (MFPA) - B e total (MFT) - C, aos 21 e 33 dias após a semeadura. Diferentes letras indicam diferenças significativas entre os substratos. Areia: $\square$; 50\% Húmus Comercial: $\square$; 100\% Húmus Comercial: $\square$; 50\% Composto Orgânico: $\square ; 75 \%$ Composto Orgânico: $\square$; 100\% Composto Orgânico:

Figura 1. Root fresh mass (MFR) - A, shoot fresh mass (MFPA) - B and total fresh mass (MFT) - C, at 21 and 33 days after sowing. Differents letters indicate significant differences between substrates. Sand: $\square$; 50\% Commercial Humus: $\square$; 100\% Commercial Humus: $\square$; 50\% Organic Compound: $\square$; 75\% Organic Compound: $\square ; 100 \%$ Organic Compound:

Nas raízes, os teores de proteínas solúveis e $\mathrm{N}$ aminossolúveis foram máximos no tratamento contendo $75 \%$ de composto orgânico (Figura 4), respectivamente, 80 e 
$40 \%$ em relação ao controle. Os teores de carboidratos solúveis (Figura 4B) foram maiores nos tratamentos 75 e $100 \%$ de composto orgânico, aumentando, em média, 100\% em comparação ao controle. E, o tratamento 100\% de composto orgânico destacou-se na produção de prolina, com incrementos de 350\%, comparando-se com as plantas controle.

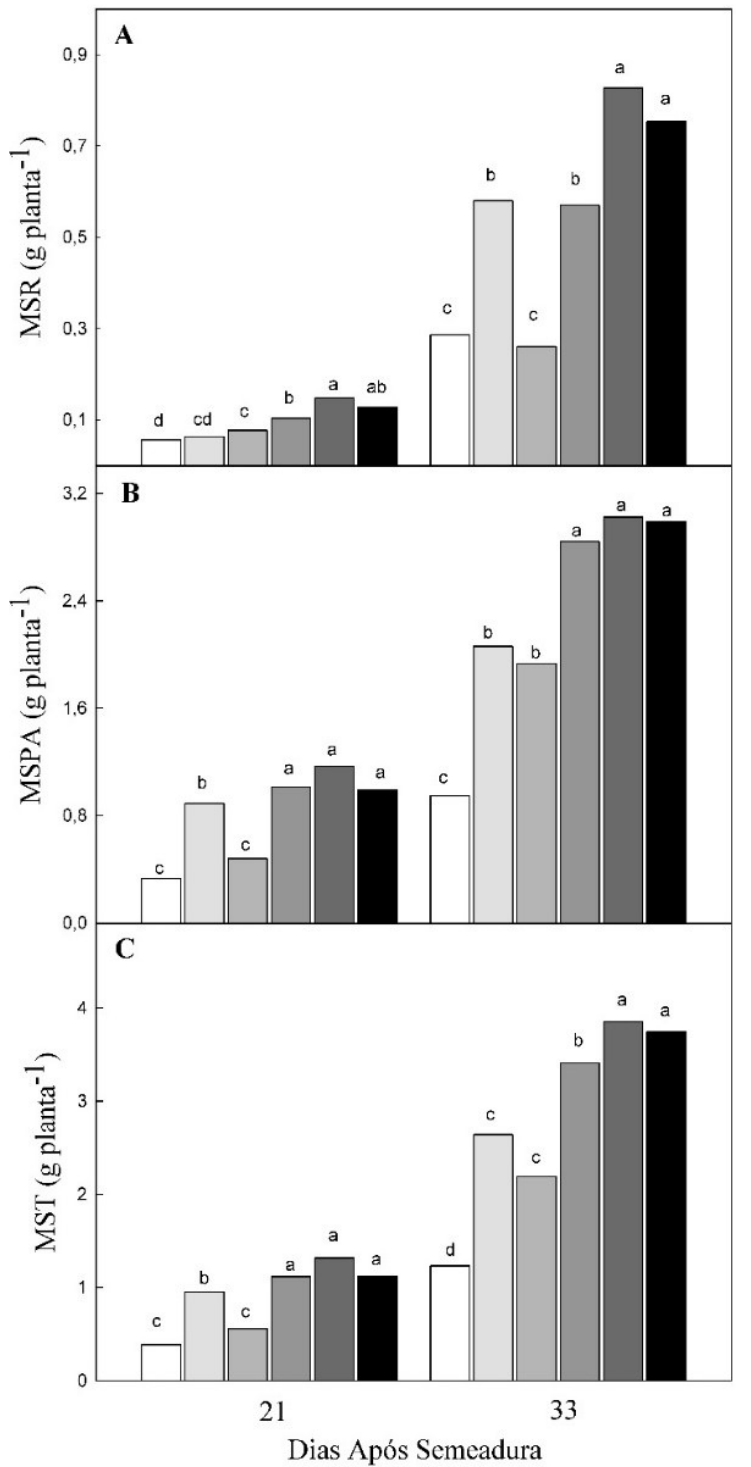

Figura 2. Matéria seca das raízes (MSR) - A, da parte aérea (MSPA) - B e total (MST) - C, aos 21 e 33 dias após a semeadura. Diferentes letras indicam diferenças significativas entre os substratos. Areia: $\square$; 50\% Húmus Comercial: $\square$; 100\% Húmus Comercial: ; 50\% Composto Orgânico: $\square$; 75\% Composto Orgânico: $\square$; 100\% Composto Orgânico:

Figure 2. Root dry mass (MFR) - A, shoot dry mass (MFPA) - B and total dry mass (MFT) - C, at 21 and 33 days after sowing. Differents letters indicate significant differences between substrates. Sand: $\square$; 50\% Commercial Humus: $\square$; 100\% Commercial Humus: $\square$; 50\% Organic Compound: $\square$; 75\% Organic Compound: $\square ; 100 \%$ Organic Compound:

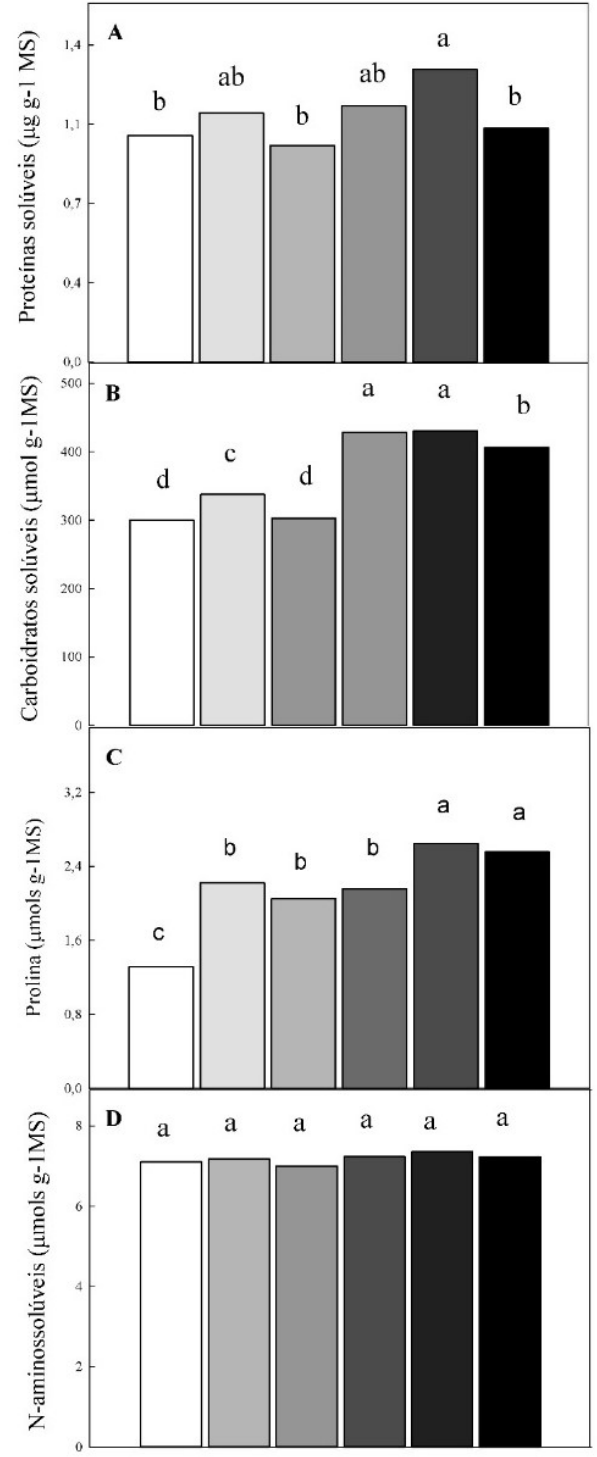

Figura 3. Teor de proteínas solúveis (A), de carboidratos solúveis (B), de prolina livre (C) e de $\mathrm{N}$-aminossolúveis (D) na folha aos 33 dias após a semeadura. Diferentes letras indicam diferenças significativas entre os substratos. Areia: Comercial: $\square$; 100\% Húmus Comercial: $\square$; 50\% Composto Orgânico: $\square$; 75\% Composto Orgânico: $\square$; $100 \%$ Composto Orgânico:

Figure 3. Soluble proteins (A), soluble carbohydrates (B), Proline (C) and free amino acyds (C), in leaves at 33 days after sowing. Differents letters indicate significant differences between substrates. Sand: $\square$; 50\% Commercial Humus: $\square$; 100\% Commercial Humus: $\square$; 50\% Organic Compound: $\square$; 75\% Organic Compound: $\square$; 100\% Organic Compound:

\section{DISCUSSÃO}

As plantas crescidas em concentrações de Nitrogênio total menores, no caso do tratamento areia (tratamento controle) e húmus comercial, tiveram valores menores de matéria fresca do que aquelas expostas às maiores concentrações de nitrogênio (composto orgânico). Portanto, as baixas concentrações de nitrogênio foram, provavelmente, os fatores mais limitantes do crescimento, assim como constatou Feijão et al. (2013). 


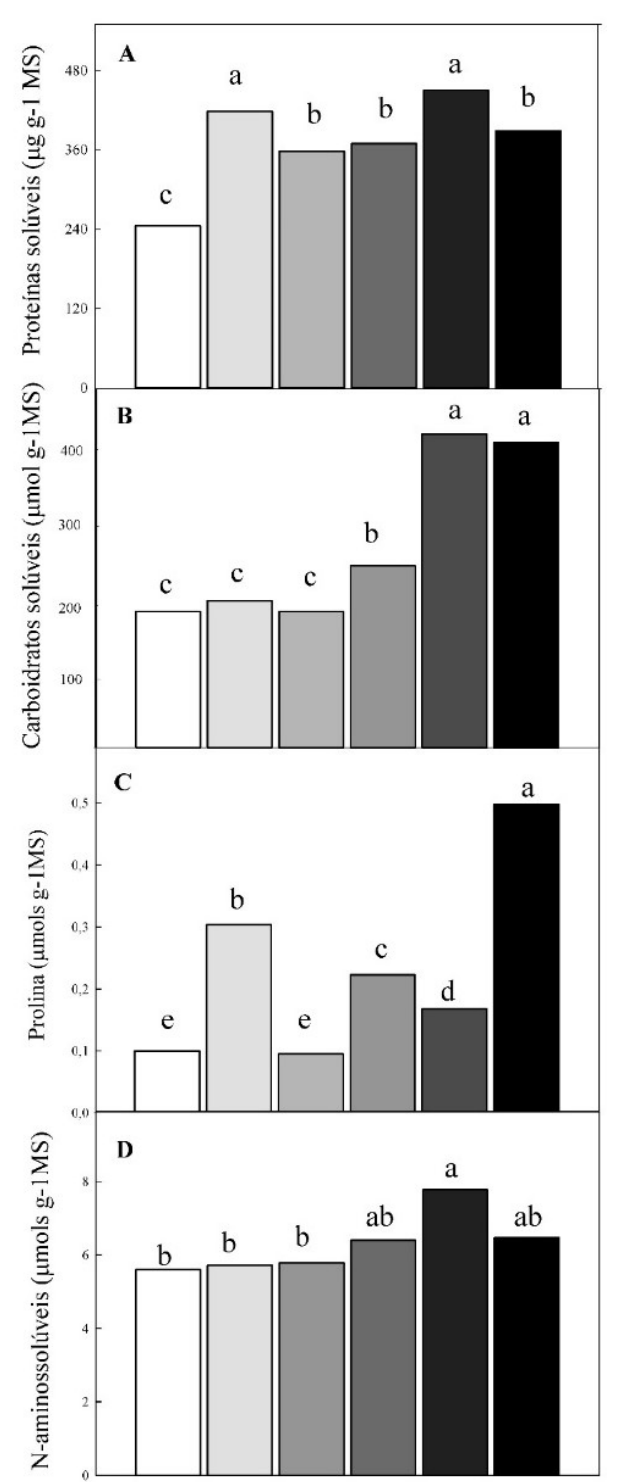

Figura 4. Teor de proteínas solúveis (A), de carboidratos solúveis (B), de prolina (C) e de n-aminossolúveis (D) na raíz aos 33 dias após a semeadura. Diferentes letras indicam diferenças significativas entre os substratos. Areia: $\square$; 50\% Húmus Comercial: 100\% Húmus Comercial: $\square$; 50\% Composto Orgânico: 75\% Composto Orgânico: $\square$; 100\% Composto Orgânico:

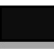

Figure 4. Soluble proteins (A), soluble carbohydrates (B), Proline (C) and free amino acyds (C), in roots at 33 days after sowing. Differents letters indicate significant differences between substrates. Sand: $\square$; 50\% Commercial Humus: $\square ; 100 \%$ Commercial Humus: $\square$; 50\% Organic Compound: $\square$; 75\% Organic Compound: $\square ; 100 \%$ Organic Compound:

A literatura aponta a importância do nitrogênio para o crescimento das plantas, sendo a deficiência desse elemento um fator importante para a rápida inibição (DING et al., 2010). De modo geral, a adição de nitrogênio melhora a produção e o crescimento das plantas, pois ele é constituinte de muitas biomoléculas, como proteínas, ácidos nucleicos e aminoácidos (BARHOUMI et al., 2010).

Outra explicação presente na literatura é que o nitrogênio é um nutriente indispensável para a molécula de clorofila, fazendo parte de sua constituição. Assim indispensável para o bom desenvolvimento da mesma, isto pode explicar uma maior massa das plantas que receberam mais nitrogênio. A maior disponibilidade desse nutriente possivelmente colaborou para uma maior produção de clorofila, assim se obtendo uma maior produção de fotoassimilados, mais energia para planta, resultando em plantas de maior porte (LANGE et al., 2018).

A matéria seca do tratamento $50 \%$ húmus foi maior que do $100 \%$ húmus. Uma possível explicação para o tratamento com uma maior concentração de nitrogênio ter um menor valor de matéria é a sua textura argilosa. Como o tratamento $100 \%$ húmus tinha uma textura muito argilosa, havia uma menor oxigenação do solo, dificultando o desenvolvimento da planta (DEDECEK; GAVA, 2005).

Os solutos orgânicos são moléculas neutras, não tóxicas que estabilizam proteínas e membranas prevenindo a desnaturação mediante as elevadas concentrações salinas, e mesmo em baixas concentrações, os solutos evitam a perda de água, o desequilíbrio iônico, reduzindo a concentração intracelular de sais (PARIDA; DAS, 2005).

Os teores de solutos orgânicos foram menores quando a planta foi submetida a baixas concentrações de nitrogênio, este processo indica que a síntese de solutos orgânicos foi limitada devido à escassez de nitrogênio (FEIJÃO et al., 2013).

Alguns estudos têm revelado que o aumento da fertilização nitrogenada pode promover o crescimento das plantas. Esse processo ocorre porque nessas condições há maior acúmulo de solutos orgânicos contendo nitrogênio, os quais associados ao nitrogênio em excesso no vacúolo contribuem diretamente para o ajustamento osmótico (DING et al., 2010)

O ajustamento osmótico constitui-se num importante mecanismo de tolerância das plantas a condições de baixo potencial hídrico no ambiente radicular, como ocorre em solos salinos. Entre os ajustes osmóticos, destaca-se o aumento da produção de prolina, N-aminossolúveis, carboidratos solúveis e proteínas solúveis, que diminuem o potencial osmótico da célula de forma a produzir um alto potencial de turgescência para a manutenção do crescimento (CUNHA et al., 2013).

Diante disso, pode-se avaliar que os altos teores de nitrogênio no tratamento com composto orgânico promoveram uma produção mais elevada de solutos orgânicos, o que ajudará no ajustamento osmótico.

Nas plantas o metabolismo dos carboidratos e dos aminoácidos é co-regulado. Dessa forma, para que ocorra assimilação do nitrogênio em aminoácidos, são necessários esqueletos de carbono provenientes do metabolismo dos carboidratos. Isto pode explicar o fato dos teores de aminoácidos nas folhas terem aumentado simultaneamente com os dos carboidratos (SACRAMENTO et al., 2014).

\section{CONCLUSÕES}

O fornecimento de nitrogênio resulta em melhoria nos fatores de produção, nos teores de nitrogênio na planta e aumento da produtividade.

Os tratamentos que apresentaram maiores produções de matéria fresca e seca também mostraram maiores teores de solutos orgânicos, principalmente nos tratamentos com o composto orgânico.

Nas condições experimentais empregadas, verificou-se que o tratamento contendo $75 \%$ composto orgânico 
ocasionou o maior crescimento das plantas de Mulungu quando comparados aos demais tratamentos, ou seja, foi o melhor tratamento.

Dessa forma, o uso de composto orgânico na fertilização do mulungu se mostrou uma técnica eficiente e viável na recuperação de áreas degradas.

\section{REFERÊNCIAS}

ARAÚJO, G. H. de S.; ALMEIDA, J. R. de; GUERRA, A. J. T. Gestão Ambiental de Áreas Degradadas. Rio de Janeiro: Bertrand Brasil, 2005. 320 p.

AGRA, M. D. F.; FREITAS, P. F. D.; BARBOSA-FILHO, J. M. Synopsis of the plants known as medicinal and poisonous in Northeast of Brazil. Brasileira de Farmacognosia, João Pessoa, v. 17, n. 1, p. 114-140, 2007. DOI: http://dx.doi.org/10.1590/S0102695X2007000100021

BARHOUMI, Z.; ATIA, A.; RABHI, M.; DJEBALL, W.; ABDELLY, C.; SMAOUI, A. Nitrogen and $\mathrm{NaCl}$ salinity effects on the growth and nutrient acquisition of the grasses Aeluropus littoralis, Catapodium rigidum, and Brachypodium distachyum. Journal of Plant Nutrition and Soil Science, v. 173, p. 149-157, 2010. DOI: https://doi.org/10.1002/jpln.200800113

CARLESSO, W. M.; RIBEIRO, R.; HOEHNE, L. Tratamento de resíduos a partir de compostagem e vermicompostagem. Destaques Acadêmicos, Lajedo, v. 3, n. 4, p. 105-110, 2012.

CARVALHO, P. E. R. Mulungu (Erythrina velutina). Colombo: Embrapa Florestas, 2008. 6p.

CUNHA, M. do C. L.; GOMES, I. H. R. A. Viabilidade de sementes de Erythrina velutina Willd pelo teste de tetrazólio. Nativa, v. 3, n. 3, p. 196-200, 2015. DOI: 10.14583/2318-7670.v03n03a08

CUNHA, P. C. da; MENDES, B. S. da S.; OLIVEIRA FILHO, R. A. de; CAMARA, T. R.; WILLADINO, L. G. Crescimento, síntese de solutos orgânicos e equilíbrio iônico de plântulas de pinhão-manso sob estresse salino. Caatinga, Mossoró, v. 26, n. 3, p. 46-52, 2013.

DEDECEK, R. A.; GAVA, J. L. Influência da compactação do solo na produtividade da rebrota de eucalipto. Revista Árvore, Viçosa, v. 29, n. 3, p. 383-390, 2005.

DING, X.; TIAN, C.; ZHANG, S.; SONG, J.; ZHANG, F.; MI, G.; FENG, G. Effects of NO3 $-\mathrm{N}$ on the growth and salinity tolerance of Tamarix laxa Willd. Plant and Soil, v. 331, p. 57-67, 2010. DOI: https://doi.org/10.1007/s11104-009-0231-7

FEIJÂA, A. R.; MARQUES, E. C.; SILVA, J. C. B. da; LACERDA, C. F. de; PRISCO, J. T.; GOMES-FILHO, E. Nitrato modula os teores de cloreto e compostos nitrogenados em plantas de milho submetidas à salinidade. Bragantia, Campinas, v. 72, n. 1, p. 10-19, 2013. DOI: http://dx.doi.org/10.1590/S000687052013005000021

LANGE, A.; CAVALLI, E.; CARLETO, E. A.; BUCHELT, A. C.; CAVAlli, C.; PEREIRA, C. S. Métodos de fornecimento de nitrogênio para melhorar a produtividade na cultura do feijoeiro irrigado no Cerrado Mato-grossense. Nativa, v. 6, n. 3, p. 252-260, 2018. DOI: http://dx.doi.org/10.31413/nativa.v6i3.5057

LIMA, E. M.; CURCIO, G. R.; BONNET, A.; UHLMANN, A.; PALMA, V. H. Crescimento inicial de espécies arbóreas nativas em solos degradados e com presença de plintita no Bioma Cerrado, Brasília - DF. Nativa, Sinop, v. 6, n. especial, p. 787-794, 2018. DOI: http://dx.doi.org/10.31413/nativa.v6i0.6210

LOUREIRO, D. C.; AQUINO, A. M. de; ZONTA, E.; LIMA, E. Compostagem e vermicompostagem de resíduos domiciliares com esterco bovino para a produção de insumo orgânico. Pesquisa Agropecuária Brasileira, Brasília, v. 42, n. 7, p. 1043-1048, 2007. DOI: http://dx.doi.org/10.1590/S0100-204X2007000700018

MARTINS, K.; BRITO, P. O. B. de; GONDIM, F. A.; PONTES FILHO, R. A.; BRAGA, B. B. Análise de crescimento de plantas de Mulungu irrigadas com diferentes capacidades de campo. In: Congresso Amazônico de Meio Ambiente \& Energias Renováveis, 2, 2016, Belém. Anais... Belém: UFRA.

MONTEIRO, N. D. K. V. Avaliação das atividades antiinflamatória, anticoagulante e antiproliferativa do inibidor de quimotripsina das sementes de Erythrina velutina (EvCI). 2011. 126 f. Dissertação (Mestrado em Bioquímica) - Universidade Federal do Rio Grande do Norte, Natal, 2011.

OLIVEIRA, D. A. de; DUDA, G. P.; MENDES, A. M. S.; OLIVEIRA, R. A. de; FERNANDES, M. B. Caracterização química do solo em uma área de implantação do projeto de recuperação de áreas degradadas da Jica no município de Pedro Avelino-RN. Caatinga, Mossoró, v. 21, n. 1, p. 179-188, 2008.

ORRICO JÚNIOR, M. A. P.; ORRICO, A. C. A.; LUCAS JUNIOR, J. de; SAMPAIO, A. A. M.; FERNANDES, A. R. M.; OLIVEIRA, E. A. de. Compostagem dos dejetos da bovinocultura de corte: influência do período, do genótipo e da dieta. Brasileira de Zootecnia, Viçosa, v. 41, n. 5, p. 1301-1307, 2012. DOI: http://dx.doi.org/10.1590/S1516-35982012000500030

PARIDA, A.; DAS, A. B. Salt tolerance and salinity effects on plants: a review. Ecotoxicology and Environmental Safety, v. 60, p. 324-349, 2005.

PEDROSA, T. L.; FARIAS, C. A. S. de; PEREIRA, R. A.; FARIAS, E. T. do R. Monitoramento dos parâmetros físico-químicos na compostagem de resíduos agroindustriais. Nativa, Sinop, v. 1, n. 1, p. 44-48, 2013. DOI: $10.31413 /$ nativa.v1i1.1335

PEREIRA, C. M. da S.; ANTUNES, L. F. de S.; AQUINO, A. M. de; LEAL, M. A. de A. Substrato à base de esterco de coelho na produção de mudas de alface. Nativa, Sinop, v. 8, n. 1, p. 58-65, 2020. DOI: http://dx.doi.org/10.31413/nativa.v8i1.8018

RIBEIRO, M. D.; ONUSIC, G. M.; POLTRONIERI, S. C.; VIANA, M. B. Effect of Erythrina velutina and Erythrina mulungu in rats submitted to animal models of anxiety and depression. Brazilian Journal of Medical and Biological Research, v. 2, p. 263-270, 2006. DOI: https://doi.org/10.1590/S0100-879X2006000200013

SACRAMENTO, B. L. do; CRUZ, T. S.; SILVA, L. L.; MOTA, K. N. A. B.; AZEVEDO NETO, A. D. de. Pigmentos e teores de solutos orgânicos em plantas de aguapé sob estresse salino. Enciclopédia Biosfera, Goiânia, v. 1, n. 18, p. 3344-3354, 2014.

SILVA, T. S. da; CÂNDIDO, G. A.; FREIRE, E. M. X. Environmental degradation in semiarid brasilian: an aplication of sustainability indicators in municipalities with conservation units. Holos, Natal, v. 1, p. 182-201, 2016. DOI: https://doi.org/10.15628/holos.2016.1680 